\title{
Pacemaker Implant in a Dog with Sick Sinus Syndrome
}

\author{
Amanda Sarita Cruz Aleixo', Angélica Alfonso', Bárbara Keiko Kichise', Francisco Teixeira Neto², \\ Carolina Hagy Girotto ${ }^{2}$, André Monti Garzesi ${ }^{3}$, Leonardo Rufino Garcia ${ }^{3}$, Rubens Ramos de Andrade ${ }^{3}$ \\ \& Maria Lúcia Gomes Lourenço'
}

\begin{abstract}
Background: Sick sinus syndrome is characterized by the presence of arrhythmias, including persistent sinus bradycardia, sinus arrest and paroxysmal atrial tachyarrhythmia. It commonly occurs in elderly dogs, especially miniature schnauzers; however, it is also detected in dachshunds and pugs. Reports of clinical signs by animal owners are not always clear and precise, which may result in erroneous interpretations by veterinarians; consequently, the use of inappropriate therapies. The present work aims to describe clinical aspects and findings from tests related to sick sinus syndrome (SSS) and presents the case of a female schnauzer with SSS.

Case: A 10-year-old female dog (schnauzer, $8.6 \mathrm{~kg}$ ) attended the Veterinary Hospital of the FMVZ-UNESP - Botucatu. The owner mentioned convulsive episodes, but a thorough medical history and patient assessment revealed that the dog exhibited episodes of syncope. During the physical examination, cardiac auscultation revealed the heart rate to be 56 beats per minute (bpm), and there was a presence of pauses. Also during cardiac auscultation, a holosystolic heart murmur was verified, with a focus on the mitral and tricuspid valves. The electrocardiogram showed the presence of sinus arrest with escape rhythms, pauses of $10 \mathrm{~s}$ and the presence of bradycardia-tachycardia syndrome. A Holter monitor was used to establish the diagnosis of SSS. The patient presented with significant episodes of syncope during outpatient care, and based on the clinical manifestation, drug therapy was initiated. The prescribed medications were aminophylline $20 \mathrm{mg} /$ $\mathrm{kg}$ TID, enalapril maleate $0.5 \mathrm{mg} / \mathrm{kg}$ BID, spironolactone $1 \mathrm{mg} / \mathrm{kg}$ SID and furosemide $2 \mathrm{mg} / \mathrm{kg}$ BID. After the start of treatment, there was a reduction in the frequency of episodes of syncope. Three weeks after diagnosis, a pacemaker device was implanted. Currently, clinical signs are absent.

Discussion: Sinus node dysfunction is one of the main reasons for pacemaker implantation. It is usually diagnosed based on clinical signs and the presence of sinus bradycardia and sinus pauses in electrocardiograms or Holter monitoring. The diagnosis of SSS is limited to cases in which the patient does not present with abnormalities in an electrocardiogram. Syncope is a clinical sign commonly present in patients with dysfunction of the sinus node, and episodes of syncope were reported by the owner of the dog referred to in the present report. A thorough medical history and physical examination must be performed to diagnose SSS because erroneous diagnosis and incorrect interpretations of clinical signs can lead to the misuse of medications. The treatment of choice for SSS is an implantable pacemaker device; however, because the method is not widely used in Brazil, a second option is drug treatment. In the present report, after implantation of a pacemaker, clinical signs ceased, and the patient was in good general health and could return to her normal activities. Sick sinus syndrome is a disease commonly found in schnauzers. There is a need for detailed histories and complementary exams because the clinical signs do not always correlate with electrocardiographic findings. The implantation of a pacemaker is the treatment of choice and is effective for the condition, but its use is not uniformly accessible throughout the country.
\end{abstract}

Keywords: pauses, electrocardiogram, syncope, arrhythmias.

${ }^{1}$ Departamento de Clínica Veterinária \& ²Departamento de Cirurgia e Anestesiologia Veterinária, Faculdade de Medicina Veterinária e Zootecnia (FMVZ), Universidade Estadual Paulista (UNESP), Botucatu, SP, Brazil. ${ }^{3}$ Departamento de Cirurgia e Ortopedia, Faculdade de Medicina de Botucatu (FMB), Universidade Estadual Paulista (UNESP), Botucatu. CORRESPONDENCE: M.L.G. Lourenço [mege@fmvz.unesp.br - Tel.: +55 (014) 3880-2044]. Faculdade de Medicina Veterinária e Zootecnia FMVZ-UNESP Botucatu. Rua Prof. Doutor Walter Mauricio Correa s/n. Caixa Postal 560. Bairro Unesp. Campus Botucatu. CEP 18618-681 Botucatu, SP, Brazil 


\section{INTRODUCTION}

Arrhythmias are heart rate abnormalities stemming from the place of origin of the electrical impulse; atrial or ventricular depolarization can be attributed to a disturbance in the generation and/or conduction of an electrical impulse [1,2]. Sick sinus syndrome (SSS) is characterized by the presence of arrhythmias, including persistent sinus bradycardia, sinus arrest, and paroxysmal atrial tachyarrhythmia alternating with periods of bradycardia. It commonly occurs in older dogs, especiallyminiature schnauzers, although it is also found in pugs and dachshunds [3].

The electrocardiographic aspects of SSS are not always possible to correlate with clinical signs. In addition, symptoms such as weakness are nonspecific and may not be recognized as being caused by nodal sinus dysfunction until the implantation of a pacemaker $[4,10,15]$. Initially, individuals may remain asymptomatic. The importance of preserving synchronized ventricular contraction and a functional atrioventricular node has been emphasized in clinical trials, and the implantation of pacemakers is an effective and definitive treatment for the disease $[7,20]$.

Reports of clinical signs by animal owners are not always clear and precise, which may result in erroneous interpretation by veterinarians and, consequently, the use of inappropriate therapies that can significantly compromise the clinical condition of the patient. The present work aims to describe clinical aspects and findings from tests related to SSS and presents the case of a female schnauzer with SSS.

\section{CASE}

A 10-year-old female dog (Schnauzer, 8.6 $\mathrm{kg}$ ) attended the Veterinary Hospital of the FMVZUNESP, Botucatu, SP, Brazil. The owner mentioned convulsive episodes, but a thorough medical history and patient assessment revealed that the dog exhibited episodes of syncope.

During the physical exam, the respiratory rate was 28 breaths per minute, the heart rate was $56 \mathrm{bpm}$, and pauses were noted during cardiac auscultation. Cardiac auscultation also verified the presence of a holosystolic heart murmur and identified its focal points to be the mitral (IV/VI) and tricuspid (III/VI) valves. A complete blood count (CBC) revealed anemia (red blood cells: $4.58 \times 10^{6} / \mu \mathrm{L}$; hemoglobin: $10.9 \mathrm{~g} / \mathrm{dL}$; hematocrit: $28 \%)$ and thrombocytosis $(476.000 / \mu \mathrm{L})$.
According to biochemical tests, mild azotemia (urea: $278.5 \mathrm{mg} / \mathrm{dL}$; creatinine: $1.92 \mathrm{mg} / \mathrm{dL}$ ), hyperphosphatemia $(9.73 \mathrm{mg} / \mathrm{dL})$, hypocalcemia $(8.23 \mathrm{mg} / \mathrm{dL})$ and hyponatremia $(139.0 \mathrm{mEq} / \mathrm{L})$ were present.

The electrocardiogram showed the presence of sinus arrest with escape rhythms, pauses of $10 \mathrm{~s}$ and extensive bradycardia-tachycardia syndrome (Figure 1). An atropine test was performed by administering atropine at a dose of $0.04 \mathrm{mg} / \mathrm{kg}$ IV. An electrocardiogram was recorded $10 \mathrm{~min}$ after the atropine injection. Common practice for this test suggests that if the HR does not rise by $150 \%$, the electrocardiogram should be repeated $15 \mathrm{~min}$ after administration [5]; this second electrocardiogram was performed in the present case, and there was no response to the test. The episodes of sinus bradycardia and pauses persisted. Subsequently, ambulatory electrocardiography was performed for 24 h (i.e., using a Holter monitor) ${ }^{1}$. During the monitoring, atypical heart patterns were frequent and longlasting; these included pauses (7.553), arrhythmias and episodes of tachycardia-bradycardia, establishing the diagnosis of SSS (Figure 2). The minimum HR recorded was $28 \mathrm{bpm}$, the mean HR was $99 \mathrm{bpm}$, and the maximum HR was $250 \mathrm{bpm}$.

A Doppler echocardiogram of the patient was conducted. The Teichholz method showed a $38.6 \%$ shortening fraction and a $71 \%$ ejection fraction. The speed of the blood flow from the pulmonary valve was $96.5 \mathrm{~cm} / \mathrm{s}$, and the pressure gradient generated between the right ventricle and the pulmonary artery was 3.72 $\mathrm{mmHg}$. In the assessment of diastolic function of the mitral valve using the Doppler spectral method, we obtained the following values: $\mathrm{E}$ wave $=139.1 \mathrm{~cm} / \mathrm{s}$, $\mathrm{E}$ wave-pressure gradient $=7.74 \mathrm{mmHg}, \mathrm{A}$ wave $=$ $108 \mathrm{~cm} / \mathrm{s}$, A wave-pressure gradient $=4.73 \mathrm{mmHg}$. Subjective evaluation showed thinning of both valvular

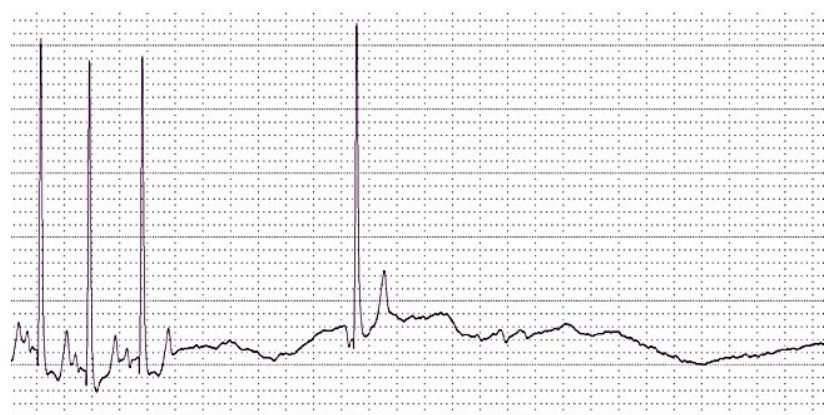

Figure 1. Electrocardiographic tracing (dog: female, schnauzer) 3 days before pacemaker implant. ECG: speed of $50 \mathrm{~mm} / \mathrm{s}$ and sensitivity $1 \mathrm{~cm}=$ $1 \mathrm{mV}$; II lead. Veterinary Cardiology Service - FMVZ-Botucatu, SP, Brazil. 


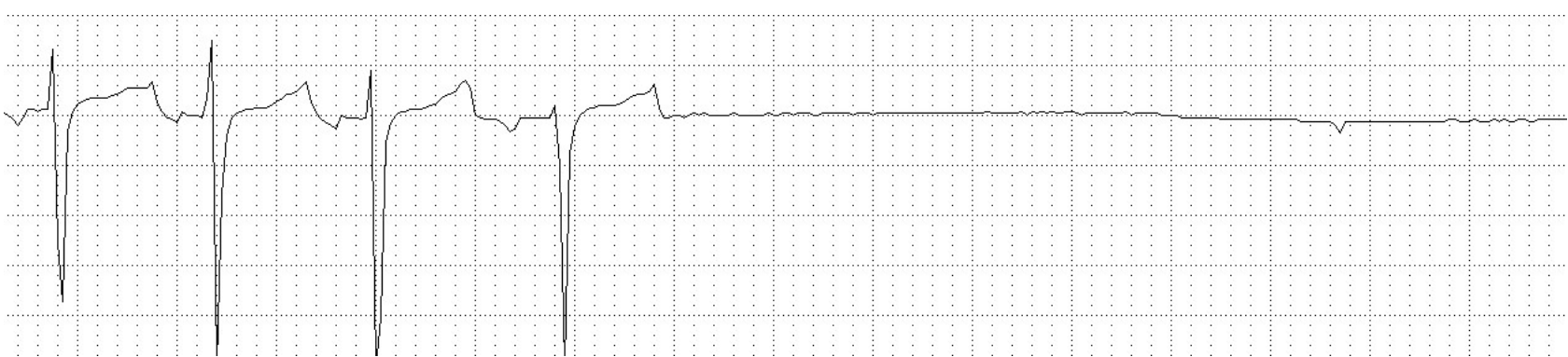

Figure 2. Tachycardia and sinus pause, then 24-h ambulatory. electrocardiogram. Veterinary Cardiology Service - FMVZ- Botucatu, SP, Brazil.

leaflets (i.e., parietal and septal) and degeneration of the same, especially in the septal leaflet. A color Doppler study revealed a mitral regurgitation speed of 534.2 $\mathrm{cm} / \mathrm{s}$ that produced a 114.1-mmHgpressure gradient between the left atrium and left ventricle.

A Doppler spectral study revealed the transaortic systolic flow velocity to be $150 \mathrm{~cm} / \mathrm{s}$, which produced a 9.04-mmHgpressure gradient between the left ventricle and the aorta. The color Doppler study revealed tricuspid regurgitation with a speed of 329.6 $\mathrm{cm} / \mathrm{s}$ that produced a $45.5-\mathrm{mmHg}$ pressure gradient between the right atrium and right ventricle (Figure 3). Based on the echocardiographic results and subjective analysis, we concluded that the patient had CHF due to the presence of blood volume overload and the high pressure gradients. The valves were degenerate.

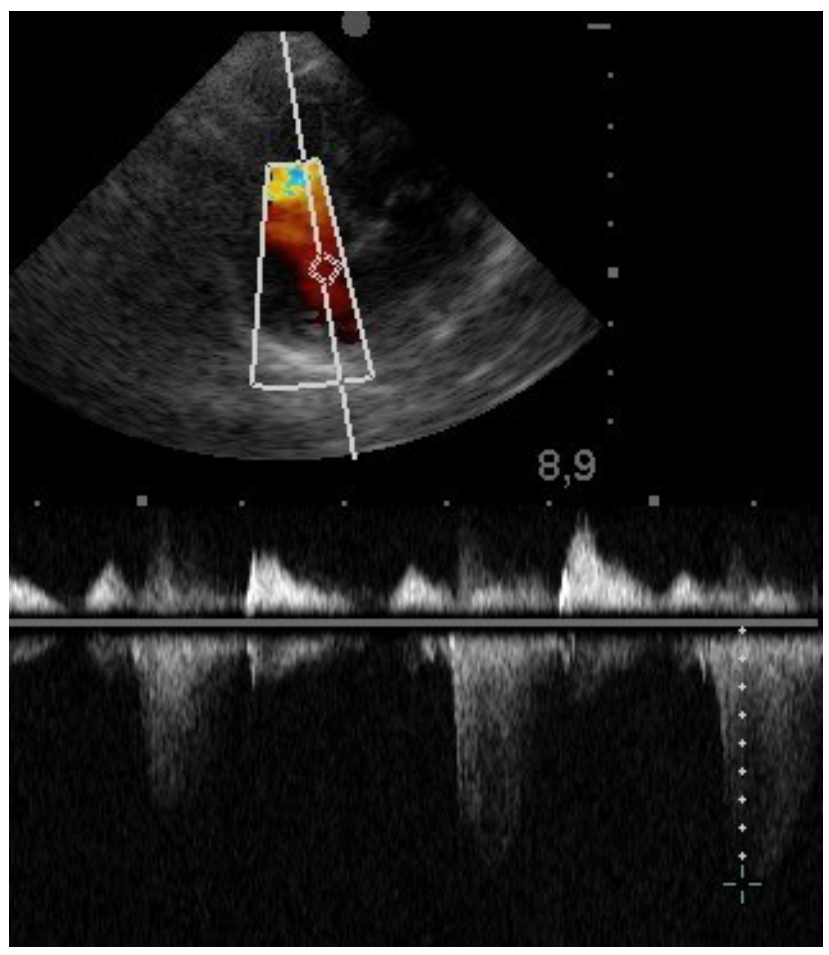

Figure 3. Echocardiographic image from color Doppler (dog: female, schnauzer) showing tricuspid regurgitation. The left apical four-chamber view (standing position). Veterinary Cardiology Service - FMVZ-Botucatu, SP, Brazil.
The patient presented significant episodes of syncope during outpatient care, and based on the clinical manifestation, drug therapy was initiated. The medication prescribed was aminophylline $20 \mathrm{mg} / \mathrm{kg}$ TID, enalapril maleate $^{2} 0.5 \mathrm{mg} / \mathrm{kg}$ BID, spironolactone ${ }^{3} 1 \mathrm{mg} / \mathrm{kg}$ SID and furosemide ${ }^{4} 2 \mathrm{mg} / \mathrm{kg}$ BID. There was a reduction in episodes of syncope during the first week after starting treatment, and the next week, the patient only exhibited episodes of presyncope. The use of drug therapy for $\mathrm{CHF}$ was performed according to the classification of ACVIM [20] and according to echocardiographic examination (i.e., mitral and tricuspid valvular degeneration, class III).

Three weeks after diagnosis, the patient underwent the recommended treatment for the disease, i.e., implantation of a pacemaker device. A consistent transvenous implantation technique was used. The dog was pre-medicated with ketamine ${ }^{5} \mathrm{mg} / \mathrm{kg}$ and midazolam ${ }^{6} 0.3 \mathrm{mg} / \mathrm{kg}$ IV. The dog was intubated and positioned in left lateral recumbency. Anesthesia was maintained using gas inhalation. The right jugular vein was surgically isolated and ligated cranially. A single-chambered endocardial pacemaker lead was inserted through a small incision in the vein and advanced under fluoroscopic guidance to the apex of the right ventricle (Figure 4). The lead was advanced until the tip contacted the right ventricle apex wall and appeared to be stable. A subcutaneous pocket was created at the ventral aspect of the thoracic incision to accommodate a generator, which was connected to the pacemaker lead. The pacemaker was made by Boston Scientific and was an Advantio model $(\mathrm{K} 082)^{7}$ [basic frequency 60-60 (BOL-ERI-ppm], magnetic frequency 100-85 (BOL-ERI-ppm), connector size IS-1 (mm), polarity UNI/BI, leads, and titanium battery). After the surgical procedure, the patient remained under observation for $24 \mathrm{~h}$. At the time of writing, the clinical signs have ceased. An electrocardiogram was performed after the pacemaker was implanted, and it showed significant improvement of the arrhythmias (v 5). A Holter test was carried out after the procedure and revealed a reduction in the frequency of arrhythmias. 


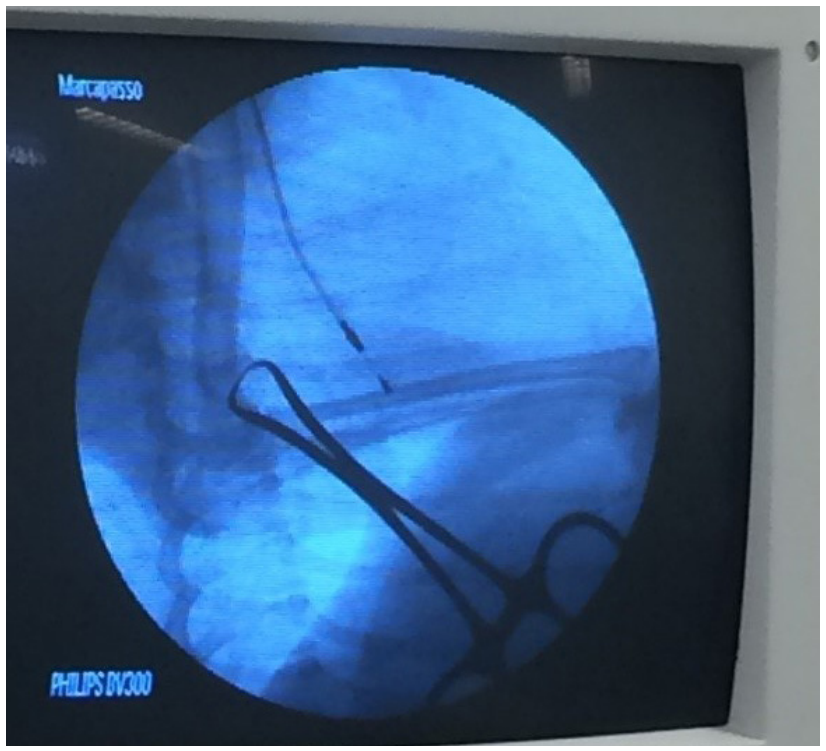

Figure 4. A single-chambered endocardial pacemaker lead was inserted and advanced under fluoroscopic guidance to the apex of the right ventricle. The lead was advanced until the tip contacted the right ventricle apex wall.Veterinary Cardiology Service - FMVZ-Botucatu, SP, Brazil.

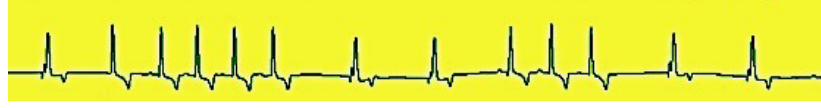

Figure 5. Electrocardiographic tracing (dog: female, schnauzer) 7 days post pacemaker implant. Veterinary Cardiology Service - FMVZ-Botucatu, SP, Brazil. Arrow: spike pacemaker. ECG: speed of $50 \mathrm{~mm} / \mathrm{s}$ and sensitivity $1 \mathrm{~cm}=1 \mathrm{mV}$; II lead..

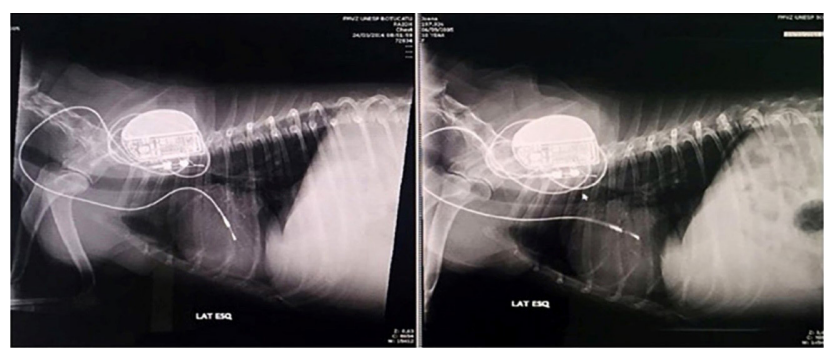

Figure 6. The image in pacemaker implant in thoracic radiographs, laterolateral view (left lateral) of a dog (female, schnauzer).

\section{DISCUSSION}

Sinus node dysfunction is one of the main reasons for implanting a pacemaker [4]. It is usually diagnosed based on clinical signs and the presence of sinus bradycardia and sinus arrest during an electrocardiogram or Holter monitoring [5]. During the present patient's 24-h Holtermonitoring, we primarily observed escape rhythms, episodes of significant pauses lasting up to $10 \mathrm{~s}$, and episodes of tachycardia-bradycardia.

SSS has been described in various dog breeds, such as pugs, dachshunds, cocker spaniels and West Highland white terriers, but femaleminiature schnauzers seem to be the most affected [7,11]; syncope is a clinical sign commonly present in patients with sinus node dysfunction $[12,18,20]$. Episodes of syncope were reported by the owner of the female schnauzer referred to in the present report, and throughout the patient's care, syncope was present.

Initially, the patient was being treated by a veterinarian who initiated drug therapy with a phenobarbital because he believed that the patient exhibited convulsive episodes. A thorough medical history and physical examination must be performed to diagnose SSS because erroneous diagnosis and incorrect interpretation of clinical signs can lead to misuse of medications.

A variety of electrocardiographic manifestations, including atrial bradyarrhythmia, atrial tachyarrhythmia alternating with periods of bradyarrhythmia and tachyarrhythmia [2,3], pauses ( $>3 \mathrm{~s})$, atrioventricular conduction disturbances (BAV of 1st and 2nd degree) and escape rhythms can be present [25]. SSS is often associated with intermittent episodes of tachyarrhythmias such as atrial fibrillation, which is referred to as tachycardia-bradycardia syndrome $[1,5,6]$, and can be diagnosed through of the use of a Holtermonitor to observe significant arrhythmic episodes compatible with SSS.

Echocardiography is a useful additional examination in the diagnosis of valvular diseases. The examination allows assessment the severity of the disease and its classification as mild, moderate or severe based on the characteristics of the stream regurgitant and atrial size $[4,16,21]$. In human patients, valve thickening is an important prognostic marker, reflecting the severity of the injury [17,24].

A systolic murmur is a related class of heart failure that involves valvular disease and is accompanied by chronic, progressive thickening and retraction of the valve cusps, thereby increasing the hole and, consequently, the murmur [16]. Doppler echocardiographic examination was employed to evaluate the patient following the diagnosis of a murmur based on cardiac auscultation. In addition, the patient presented with echocardiographic findings compatible with mitral and tricuspid valve disease.

Patients with SSS may present clinical signs of congestive heart failure (CHF). $\mathrm{CHF}$ usually results from structural or functional cardiac disease, which impairs the ability of the heart to maintain its functions properly $[9,13,14]$. In the present report, drug therapy for $\mathrm{CHF}$ was initiated because the patient presented clinical signs compatible with right $\mathrm{CHF}$. 
The treatment of choice for the disease is an implantable pacemaker device [23,26]; however, because the method is not widely used in Brazil, a second option is drug treatment. The animal exhibited a favorable response to surgical treatment thus far; there was a reduction in the extent and frequency of episodes of syncope.

Studies with pharmacological tests to predict SSS revealed significant increases in heart rate after the administration of isoproterenol in patients without dysfunction of the sinus node. Therefore, an at most mildly increased heart rate following isoproterenol administration may be a characteristic of patients with SSS $[8,10,18]$.

Technological innovations in pacemaker devices provide improvements in maximum heart rate, reduction of exercise intolerance and suppression of arrhythmias [6,7]. The ideal stimulation mode for symptomatic bradycardia caused by dysfunction of the sinus node is still controversial [22]. In the present report, after implantation of a single-chamber pacemaker (Figure 6), clinical signs ceased, and the patient was in good general condition and could return to her normal activities.

A one year has passed after the surgical procedure and the patient is well at the present moment.

Sick sinus syndrome is a disease commonly found in schnauzers. There is a need for detailed histories and complementary exams because the clinical signs do not always correlate with electrocardiographic findings and, when misunderstood, can result in an erroneous diagnosis and worsening of clinical signs in the patient. The implantation of a pacemaker is the treatment of choice and is effective for SSS.

\author{
MANUFACTURERS \\ ${ }^{1}$ Cardios. São Paulo, SP, Brazil. \\ ${ }^{2}$ Laboratório Teuto. Anápolis, GO, Brazil. \\ ${ }^{3}$ Laboratórios Pfizer. Guarulhos, SP, Brazil. \\ ${ }^{4}$ Sanofi. São Paulo, SP, Brazil. \\ ${ }^{5}$ Syntec. Santana de Parnaíba, SP, Brazil. \\ ${ }^{6}$ Roche Diagnóstica. São Paulo, SP, Brazil. \\ ${ }^{7}$ Boston Scientific. San Jose, CA, USA.
}

Declaration of interest. The authors report no conflicts of interest. The authors alone are responsible for the content and writing of the paper.

\section{REFERENCES}

1 Adán V. \& Crown L.A. 2003. Diagnosis and Treatment of Sick Sinus Syndrome. American Family Physician. 67(8): 1725-1732.

2 Andrade J.N.B.M., Lempek M.R. \& Ferian P.E. 2012. Síndromedo nó sinusal em um schnauzer - relato de caso. In: $22^{\circ}$ Seminário de Iniciação Cientifica da UDESC (Florianópolis, Brasil). p.118.

3 Aung T.T., Roberto E.S. \& Wase A. 2016. Absent Left Main Coronary Artery and Separate Ostia of Left Coronary System in a Patient with Holt-Oram Syndrome and Sinus Node Dysfunction. American Journal Case Reports. 17:93-96.

4 Cheng A. \& Tereshchenko L.G. 2011. Evolutionary innovations in cardiac pacing. Journal of Electrocardiology. 44: 611-615.

5 Choudhury M., Boyett M.R. \&Morris G.M. 2015. Biology of the Sinus Node and its Disease. Arrhythmia \& Electrophysiology Review. 4(1): 28-34.

6 Conde C.A., Leppo J., Lipski J., Stimmel B., Litwak R., Donoso E. \& Dack S. 1973. Effectiveness of Pacemaker Treatment in the Bradycardia-Tachycardia Syndrome.The American Journal of Cardiology. 32: 209-214.

7 Estrada A. H., Pariaut R., Hemsley S., Gatson B.H. \& Moise N.S. 2012. Atrial-Based Pacing for Sinus Node Dysfunction in Dogs: Initial Results. Journal of Veterinary Internal Medicine. 26: 558-564.

8 Freitas R.R., Stopiglia A.J., Fantoni D.T., Simões E.A., Larsson M.H.M.A., Jatene F.B., Barbusci L.O.D., Aneli E. \& Irino E.T. 2002. Implantation of pacemaker in dog - Case report. Continuous Education Journal. 5(2): 164-170.

9 Hesselson A.B., Parsonnet V., Bernstein A.D. \& Bonavita G.J. 1992. Deleterious Effects of Long-Term SingleChamber Ventricular Pacing in Patients with Sick Sinus Syndrome: The Hidden Benefits of Dual-Chamber Pacing. Journal of the American College of Cardiology. 19:1542-1549.

10 Yamaki F.L. \& Larsson M.H.M.A. 2015. Cardiac arrhythmias. In: Jericó M.M., Andrade Neto J.P. \& Kogica M.M. (Eds). Tratado de Medicina Interna de Cães e Gatos. Rio de Janeiro: Roca, pp.1147-1148.

11 Johnson M.S., Martin M.W.S. \& Henley W. 2007. Results of pacemaker implantation in 104 dogs. Journal of Small Animal Practice. 48: 4-11.

12 Kaplan B.M., Langendorf F., Lev M. \& Pick A. 1973. Tachycardia-Bradycardia Syndrome (So-Called "Sick Sinus Syndrome"). The American Journal of Cardiology. 31: 497-508. 
13 Medical A.S. 2005. Biventricular pacing (cardiac resynchronization therapy): an evidence-based analysis. Ontario Health Technology Assessment Series. 5(13): 21-53.

14 Mitrani R.D., Simmons J.D., Interian A., Castllanos A. \& Myerburg R.J. 1999. Cardiac pacemakers: current and future status. CurrentProblems in Cardiology. 24(6): 348-355.

15 Moreira D.A.R., Sousa A.G.M.R., Valente P. \& Leone E.H. 2004. Efeitos da estimulação com corrente elétrica contínua pulsátil sobre as propriedades eletrofisiológicas atriais. Estudo experimental da fibrilação atrial em cães. Arquivos Brasileiros de Cardiologia. 83: 26-33.

16 Muzzi R.A.L., Muzzi L.A.L., Araújo R.B. \& Lázaro D.A. 2009. Doença crônica da valva mitral em cães: avaliação clínica funcional e mensuração ecocardiográfica da valva mitral. Arquivo Brasileiro de Medicina Veterinária e Zootecnia. 61(2): 337-344.

17 Nakayama T., Wakao Y., Nemoto H., Uechi M., Kageyama T., Muto M. \& Takahashi M. 1996. Mitral valveprotrusionassessedby use ofB-modeechocardiography in dogswith mitral regurgitation. American Journal of Veterinary Research. 57: 791-797.

18 Park J.K., Park J., Uhm J.S., Pak H.N., Lee M.H. \& Joung B. 2015. Combined Algorithm Using a Poor Increase in Inferior P-Wave Amplitude During Sympathetic Stimulation and Sinus Node Recovery Time for the Diagnosis of Sick Sinus Syndrome. Circulation Journal. 79: 2148-2156.

19 Qu J., Plotnikov A.N., Danilo P., Shlapakova I., Cohen I.S., Robinson R.B. \& Rosen M.R. 2003. Expression and Function of a Biological Pacemaker in Canine Heart. Circulation. 107: 1106-1109.

20 Rubenstein J.J., Schulman C.L., Yurchak P.M. \& Desanctis R.W. 1972. Clinical Spectrum of the Sick Sinus Syndrome. Circulation. 46: 5-13.

21 Soares E.C., Larsson M.H.M.A. \& Yamato R.J. 2005. Chronic valvular disease: correlation between clinical, electrocardiographic, radiographic and echocardiographic aspects in dogs. Arquivo Brasileiro de Medicina Veterinária e Zootecnia. 57: 436-441.

22 Sweeney M.O., Hellkamp A.S., Ellenbogen K.A., Greenspon A.J., Freedman R.A., Lee K.L. \& Lamas G.A. 2003. Adverse Effect of Ventricular Pacing on Heart Failure and Atrial Fibrillation among Patients With Normal Baseline QRS Duration in a Clinical Trial of Pacemaker Therapy for Sinus Node Dysfunction. Circulation. 107: 2932-2937.

23 Tasaki H., Ashizawa N., Nagao S., Fukushima F., Furukawa R., Fukae S. \& Maemura K. 2015. Effective Management of Atrioventricular Interval for Paroxysmal Atrial Fibrillation That Developed After DDDR Pacemaker Implantation in a Sick Sinus Syndrome Patient. International Heart Journal Association. 56(5): 558-563.

24 Teshima K., Asano K., Iwanaga K., Koie H., Uechi M., Kato Y., Kutara K., Kanno N., Edamura K., Kasegawa A. \& Tanaka S. 2007. Evaluation of left ventricular Tei Index (Index of myocardial performance) in healthy dogs and dogs with mitral regurgitation. The Journal of Veterinary Medical Science. 69: 117-123.

25 Tilley L.P. \& Smith Jr. F.W.K. 2015. Sick Sinus Syndrome. In: Tilley L.P. \& Smith Jr. F.W.K. (Eds). Blackwell's five minutes veterinary consult: canine and feline. 6th edn. Rio de Janeiro: Wiley Blackwell, pp.1225-1226.

26 Toff W.D., Camm J. \& Skehan D.J. 2005. Single-Chamber versus Dual-Chamber Pacing for High-Grade Atrioventricular Block. The New England Journal of Medicine. 353(2): 145-155. 